\title{
TREALOSE E TREALASE EM TENEBRIO MOLITOR L.
}

\author{
CRISTINA PIEDRAS LOPES e GILBERTO G. VILLELA
}

Instituto Oswaldo Cruz, Rio de Janeiro, Guanabara

Sumário: Foi estudada a concentração em trealose e a atividade em trealase do Tenebrio molitor $\mathrm{L}$. durante as tres fases da metamorfose (larva, ninfa, imago). Verificou-se que na larva e no adulto os valores são mais elevados conforme a curva da fig. 3. A trealose foi expressa em $\mathrm{mg} / \mathrm{g}$ de Tenebrio e a trealose por $\mu \mathrm{g}$ de glicose $/ \mathrm{mg}$ proteina.

\section{INTRODUÇÃO}

$A$ trealose é um dissacarídeo ( $<-\mathrm{D}$ a trealase (glico-hidrolase, E.C. 3, 2, $1,28)$ é a enzima que cinde hidroliticamente a trealose em duas moléculas de glicose (trealose $+\mathrm{H}_{2} \mathrm{O}=$ $2 \mathrm{D}$ glicose).

A trealose foi encontrada na hemolinfa de todos os insetos em que foi pesquisada, a quantidade variando enormemente, dependendo das condições de alimentação. Outros tecidos também contém trealose e 0 corpo gorduroso é o mais rico de todos. A degradação da trealose se faz unicamente pela clivagem hidrolítica e a trealase é a enzima específica para esse processo. A síntese da trealose se faz no corpo gorduroso onde é armazenada e utilizada pela hemolinfa quando necessário. Nesse caso a enzima trealase atua liberando a glicose para os gastos energéticos do animal. A trealose tem portanto, no inseto, uma função análoga à do glicogênio dos animais superiores (Candy e Kilby). A síntese desse açúcar é regulada pelo hormônio do corpo cardíaco a partir do glicogênio. Em pequenas concentrações pode inibir essa síntese (Gelperin). Durante a metamorfose a diminuição da secreção tanto do corpo cardíaco como do corpo alado, influenciam a síntese indireta da trealose que pode ser ativada ou inibida, entrando assim no esquema da sua regulação geral.

A possibilidade de cisão fosforólica por meio de uma enzima como em bactérias não foi ainda demonstrada para a trealose.

1 Entregue para publicação em 1 de novembro de 1972.

Trabalho do Laboratório de Bioquímica do Departamento de Química e Terapêutica Experimental. 
Este açúcar não tem ação de transferase (transferência de oses) sobre compostos hidroxilados.

A trealose foi primeiramente encontrada em fungos, leveduras e plantas primitivas. A descoberta nos insetos por Wyatt foi úm achado inesperado. Existe também em outros invertebrados como crustáceos e nos vertebrados como o homem (Courtois e Demelier) ${ }^{1}$. Constitue uma fonte de energia sobretudo na contração muscular durante o vôo.

$\mathrm{Na}$ síntese da trealose pelos insetos o grupo glicosídico aceptor da uridina difosfo glicose é a glicose-6-fosfato, o produto final sendo a trealose6-fosfato que se desfosforila para libertar a trealose sendo esta então desdobrada em 2 moléculas de glicose. Pela ação da trealose fosfato sintetase: a síntese é feita como segue:

glicose- 6 - P + UDP glicose $\rightarrow$ trealose- $6-\mathrm{P}+$ UDP. A trealose- 6- fosfatase (fosfo-hidrolase) liberta o fósforo inorgấnico como na reação:

$$
\begin{aligned}
& \text { trealose- } 6-\mathrm{P}+\mathrm{H}_{2} \mathrm{O} \rightarrow \text { trealose } \\
& + \text { fósforo inorgânico e pela ação } \\
& \text { da trealase: } \\
& \text { trealose }+\mathrm{H}_{2} \mathrm{O} \rightarrow 2 \text { glicose. }
\end{aligned}
$$

A concentração da trealose da hemolinfa é controlada hormonalmente pela secreção da glândula do córpo cardíaco. Os extratos dessa glândula fazem aumentar muito a trealase da hemolinfa mas não das substâncias redutoras, porque estimulam a fosforilase do corpo gorduroso que atua sobre o glicogênio aí existente ${ }^{2}$.

Existe um inibidor da trealase na hemolinfa que impede a ação desta enzima sobre a trealose (Friedman).
A trealase tem sido mais estudada em insetos grandes que permitem a retirada da hemolinfa com facilidade. No caso de insetos menores como o Trilo. bium e o Tenebrio a dificuldade em se obter hemolinfa fez com que se usasse o animal inteiro.

Foi nosso intuito verificar no $T_{c}$ nebrio molitor $L$. as variações da trealose e de trealase nos principais periodos da metamosfose (larva, ninfa, imago). Dutrien e Rolland obtiveram para a trealose diferenças para mais no adulto e pouco na larva e baixa da trealase na fase ninfal e aumento no adulto ${ }^{3}$. Lemonde e Villeneuve, obtiveram no Trilobium aumento da trealose na preninfa e aumento no adulto, para o animal total ${ }^{4}$.

A atividade da trealase foi por nós também determinada nas três fases do crescimento e os resultados comparados com os da trealose.

Esse coleóptero foi escolhido por não existir ainda um estudo completo a respeito em animais normais $\mathrm{e}$ submetidos ao jejum e a dietas pobres em levedura.

\section{MATERIAL E MÉTODOS}

O coleóptero Tenebrio molitor $L$. foi utilizado nos estágios de larva, pupa e imago. Os animais foram submetidos a dieta padrão segundo Fraenkel, até obtenção de uma nova geração. Criações subseqüentes foram separadas a partir destas, em dois grupos, um deles continuando na mesma dieta completa e outro em que se retirou a levedura. A determinação na levedura por nós usada indicou o valor médio de $13,7 \mathrm{mg}$ de treoalose por $\mathrm{g}$ de levedura.

Estabeleceu-se uma curva de crescimento das larvas até o animal adulto, sendo o resultado expresso na Fig. 1. Para efeito comparativo, acha-se na mesma fi- 
gura a curva publicada por Fraenkel para as larvas. As curvas de crescimento mostraram bastante semelhança no aspecto indicando assim tratar-se de espécie homogênea $(5,6)$.

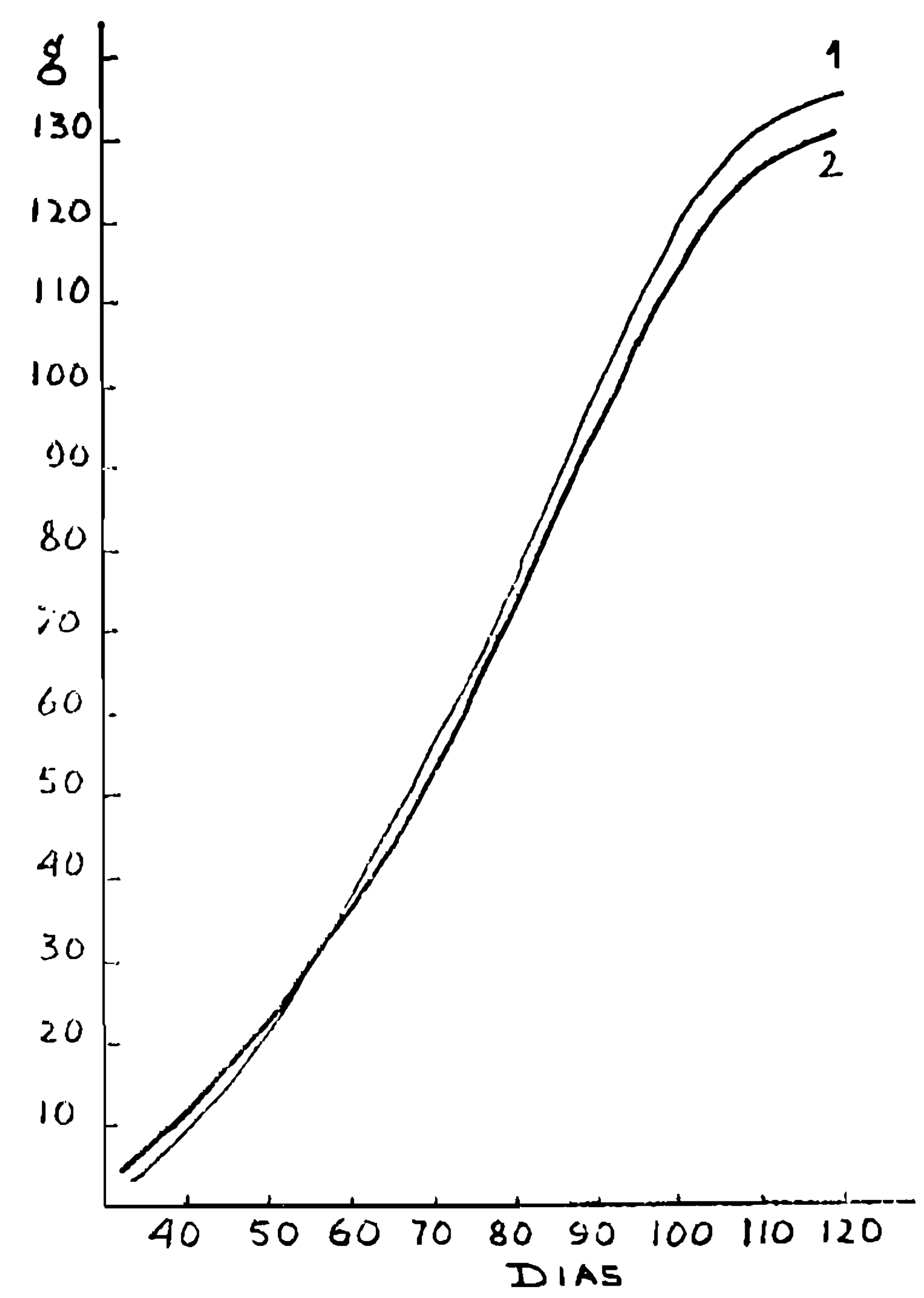

Fig. 1 - Curva de crescimento das larlas de Tenebrio molitor $L$. até a fase de ninfa. 1. Curva normal por nós obtida. 2. Curva reproduzida do trabalho de Fraenkel, et al (5), para efeito de comparação.

Utilizamos sempre o animal inteiro, bem que se tenham feitos também análises do corpo gorduroso

No caso dos imagos fora separados as asas, patas, cabeça e élitros, do corpo propriamente dito, o único utilizado nas determinações.

Para a trealase, também foram feitas determinações com a enzima purificada pelo processo usado para a Galleria mellonella por Kalf e Rieder, modificado em alguns detalhes, cujos resultados fazem parte de outro trabalho em publicação (7).

Durante a purificação da trealase estabeleceu-se o efeito das concentrações da enzima sobre a velocidade da hidrólise da trealose. A curva de Fig. 4 indica a boa proporcionalidade entre as concentraçōes da enzima em $\mathrm{ml}$ de solução e a quantidade de glicose hidrólise expressa em microg.

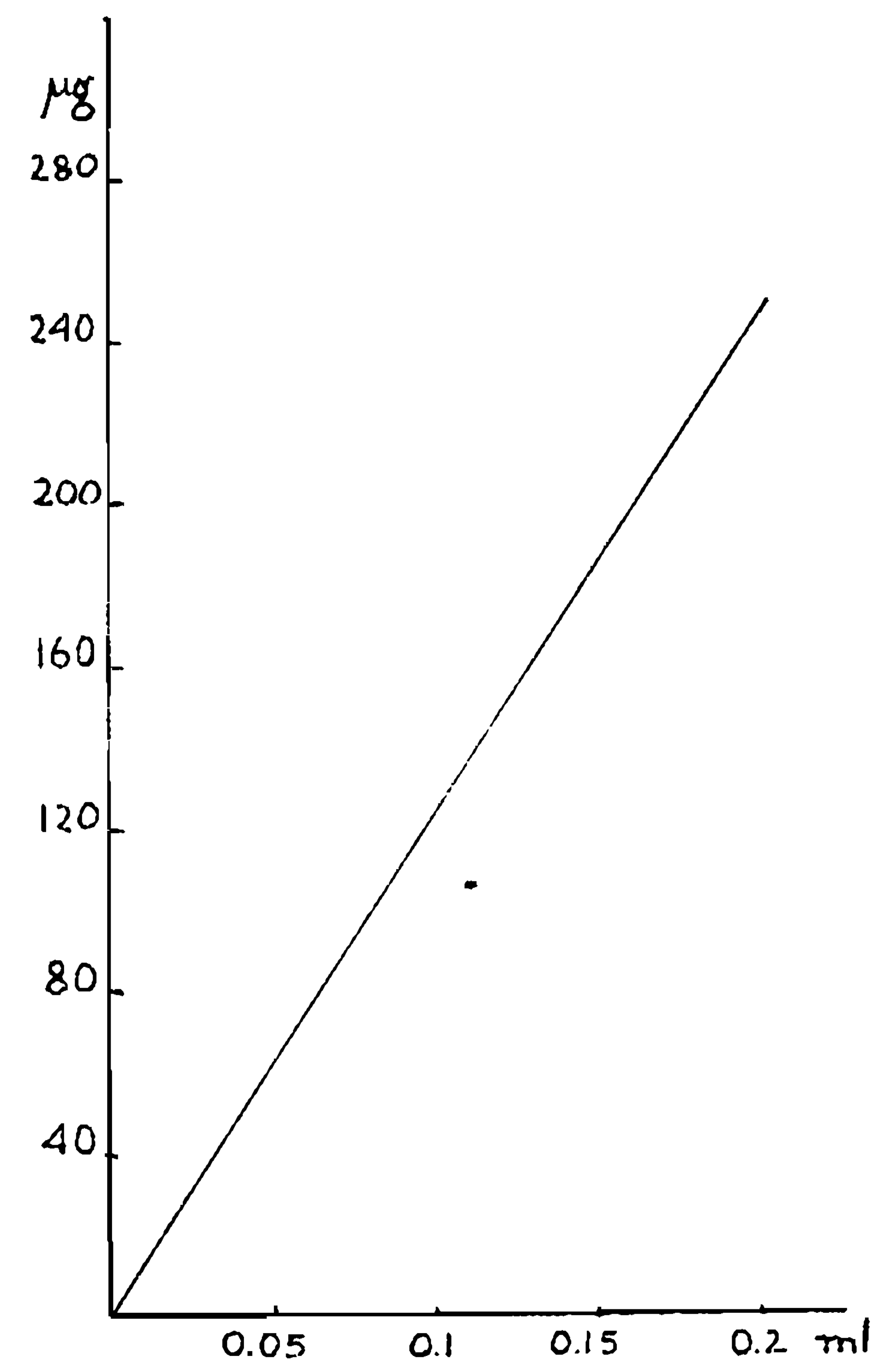

Fig. 4 - Efeito da concentração da trealose sobre a velocidade da hidrólise da trealose.

Para cada determinação usaram-se grupos de animais com aproximadamente o mesmo peso. Sendo assim foi fácil conhecer a idade pela inspeção da curva de crescimento.

As dosagens foram repetidas de modo que os valores representam a média de 7 a 30 animais.

Os homogenados correspondem ao peso de $1 \mathrm{~g}$ em $4 \mathrm{ml}$ de solução tampão pH 7.4. Utilizamos o homogenizador de vidro do tipo Potter Elvehjem com êmbolo de Teflon e movido a eletricidade com rotações variáveis. Todas as operações foram feitas em baixa temperatura, e 5 material filtrado em gase e centrifugado no centrifugo gelado internacional com $2.000 \mathrm{~g}$ durante 10 minutos. Os sobrenadantes serviram às dosagens, tendo-se o cuidado de isolar a camada superficial de gordura. Os homogenados foram prepara- 
dos a partir de $1 \mathrm{~g}$ te Tenebrio homogenado em $3,7 \mathrm{ml}$ de tainpão fosfato $\mathrm{pH} 6,0$ e o volume final completado para $4 \mathrm{ml}$. O sobrenadante foi tratado com $1 \mathrm{ml}$ da solução de hidroxido de bário $0,3 \mathrm{~N}$ e $1 \mathrm{ml}$ da solução de sulfato de zinco a $5 \%$. Conforme a técnica de Somogyi (8) e centrifugado. Uma alíquota $(1,5 \mathrm{ml})$ do sobrenadante foi adicionada $15 \mathrm{ml}$ de etanol a $66 \%$, aquecido a $75^{\circ} \mathrm{C}$ durante 15 minutos para precipitação do glicogênio Após resfriado e centrifugado, o sobrenadante foi evaporado a seco e o resíduo tratado com $1 \mathrm{ml}$ de ácido sulfúrico $0,1 \mathrm{n}$ durante 10 minutos a $100^{\circ} \mathrm{C}$, para a hidrólise da sacarose e glicose-1-fosfato eventualmente presentes $(9)$.

O extrato foi a seguir alcalizado com $1 \mathrm{ml}$ de $\mathrm{NaOH} 6 \mathrm{~N}$ e aquecido a $100^{\circ} \mathrm{C}$ durante 10 minutos para a destruição dos glicídios redutores. A trealose presente foi então dosada pelo método da difenilamina em etanol na presença de ácido hidroclórico, conforme o método, de Abreu et al. (10). Após 1 hora no banho-Maria fervente, esfria-se e lê-se no colorímetro fotcelétrico Klett com o filtro, vermelho $(670 \mathrm{~nm})$. Os resultados são multiplicados por 1,42 para se ter em trealose amostra ou lidos na curva de referência reproduzida na F.2.

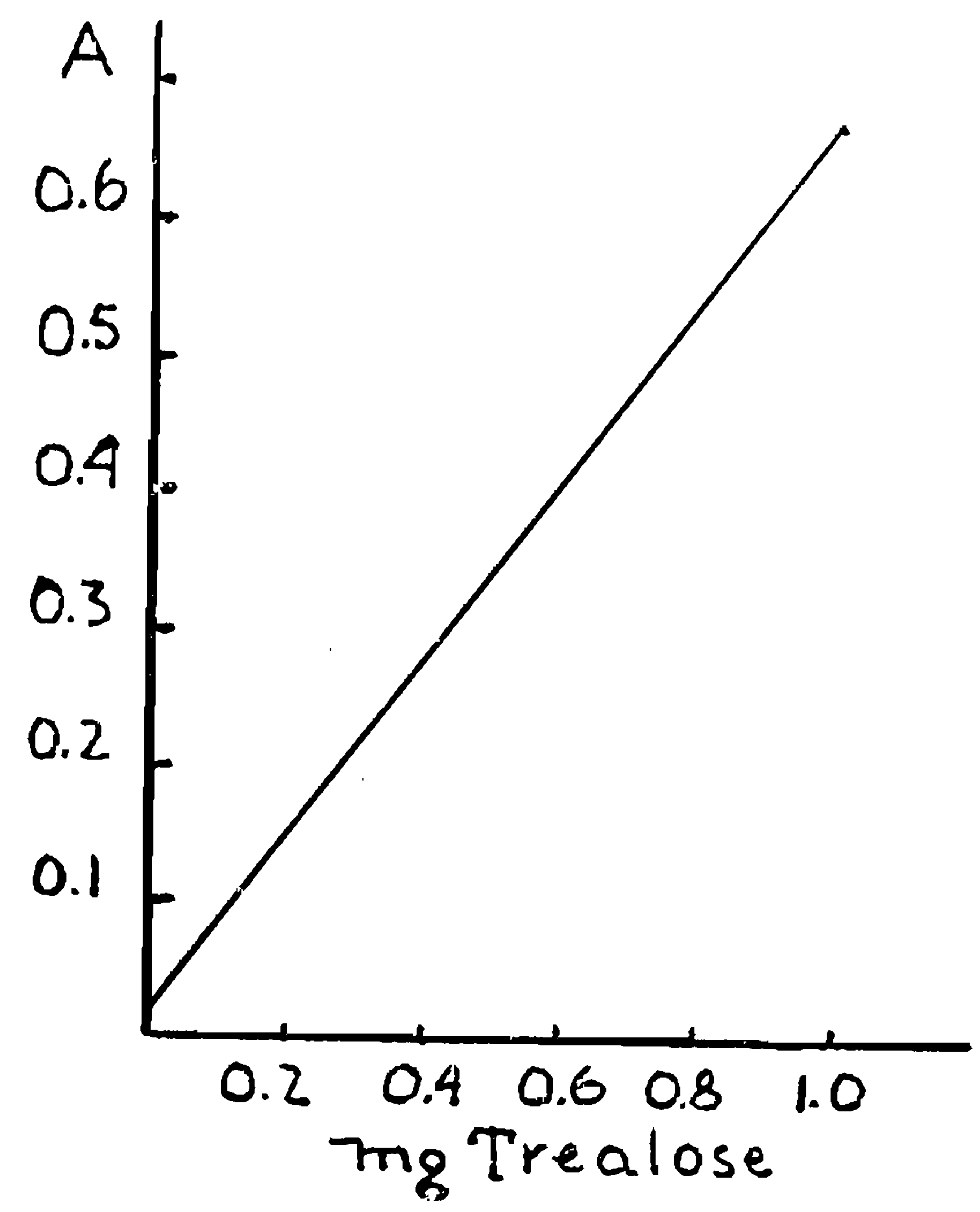

Fig. 2 - Curva de referência para a Trealose.
A atividade de trealase foi avaliada pela ação do extrato preparado com tampão Tris $\mathrm{pH} 6,5$ sobre a trealose adicionada $(1,2 \times 11,2 \times 10-7$ moles $)$. O tempo de incubação ótimo foi de 2 horas a $37^{\circ} \mathrm{C}$. A glicose hidrolisada foi determinada pelo método de redução do ferricianeto de potássio de Kingsly e Reinhold (11) e as proteínas dosadas segundo Lowry e colaboradores (12) e os resultados expressos en? unidades, sendo 1 unidade igual a 1 microg de glicose liberada por $\mathrm{mg}$ de proteína.

\section{RESULTADOS E CONCLUSÕES}

O presente estudo é baseado no Tenebrio molitor L. criado no Laboratório a partir de uma amostra homogenea. Assim teve-se o cuidado de mantê-la em temperatura pouco variável e ao abrigo da luz. Essas condições são importantes e foram bem estabelecidas por Fraenkel quanto ao valor da dieta e por Lecleroq sobre as diversas condições e as raças de Tenebrio ${ }^{13}$.

Fraenkel demonstrou que a tiamina e a carnitina são fatores indispensáveis ${ }^{14,15} \mathrm{e}$ a levedura que os contém em abundância deve ser portanto adicionada à dieta rica em carboidratos que é a proposta para a criação regular desses insetos e foi a que usamcs em nosso trabalho. As determinações da trealose, trealase e proteínas foram realizadas com número elevado de animais no total de 595 sendo para trealose de 292 larvas, $60 \mathrm{pu}$ pas e 41 adultos e para a trealase de 116 larvas, 40 pupas e 46 adultos. Para se saber a idade aproximada foi estabelecida uma curva de crescimento de animais alimentados com a dieta completa começando em 20 dias e terminando em 170 dias. O aspecto da curva é semelhante ao das curvas obtidas por Fraenkel. 
A dieta completa foi constituída por biscoitos, farelo, vitaminas de complexo B e pó de levedura $(5 \%$ de dieta total). O pó de levedura foi preparado a partir de levedura fresca Fleishman seca na estufa. Este pó mostrou conter $13,7 \mathrm{mg}$ de trealose por $\mathrm{g}$ de levedura. Tanto a trealose como a trealase foram determinadas em grupos de animais pesando $22.150 \mathrm{mg}$ (larvas), $135-87 \mathrm{mg} \quad$ (pupas e $80 \mathrm{mg}$ (adulto) conforme indicado no gráfico da Fig. 3.

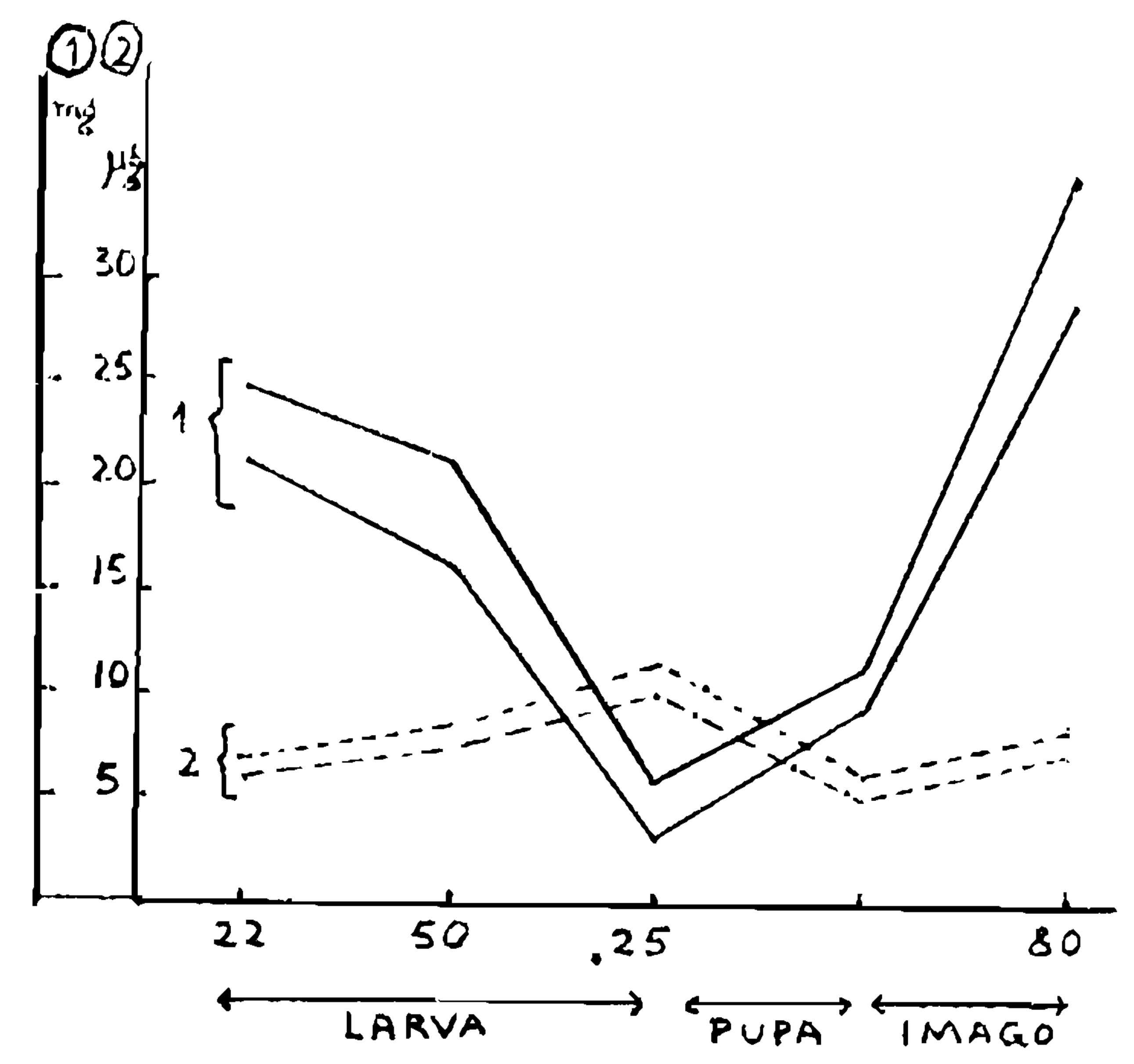

Fig. 3 - Variações da trealose e trealase durante a metamorfose. 1. Curvas para a trealase referidas em ug de glicose $/ \mathrm{mg}$ proteína. 2. Trealose em $\mathrm{mg}$ por g de Tenebrio.

A metamorfose dos insetos holometabólicos como o Tenebrio se processa em 3 fases nítidas, que apresentam características próprias. $\mathrm{Na}$ fase larval que é longa, o corpo gorduroso se mostrou rico em trealose e trealase. A glicose proveniente da alimen- tação é rapidamente convertida em trealose que é sintetizada pelos caminhos semelhantes aos descritos para a síntese da trealose da levedura por Cabib e Leloir, isto é através a trealose fosfato.

As determinações foram feitas no animal inteiro, nas três fases principais e revelaram uma curva característica que se sobrepõe às obtidas para a citocromo oxidase da drosophila e do consumo em $\mathrm{O}$ do bicho da seda. $O$ adulto contém mais do que a pupa, tanto trealose como trealase. No Tenebrio em que o imago tem vida curta e o vôo é limitado, as necessidades de energia proveniente da glicose são relativamente menores do que em Phor. mia onde toda a trealose da hemolinfa é utilizada para o vôo. O Tenebrio adulto deve usar a glicose pela cisão de trealose para compensar as necessidades, respiratórias que aumentam muito nessa fase. Dutrien já havia, também notado que o imago tinha mais trealase do que a larva, mas não estudou todas as fases nem as variações com a dieta. Em outros insetos como o Trilobium essas variações durante a metamorfose foram também assinaladas.

As nossas determinações foram feitas em 393 animais para a trealose e 202 para a trealase que se acham colocadas em gráfico para favorecer a comparação entre as três fases (Fig. 2). A alimentação com levedura favoreceu significativamente o armazenamento da trealose e estimulou a atividade da trealase. Tanto a trealose quanto a trealase foram determinadas em grupos de animais pesando 22-150 (larvas) 87-125 (pupa) e 80mg (adulto). 
O estudo feito com a trealase purificada mostrou que existem algumas diferenças nas propriedades quando se compara com a trealase purificada prcveniente de cutras fontes. Assim, a inibição pelo manitol descrita para a trealase do Aspergillus oryzae, não foi encontrada por nós para enzima do Tenebrio. $\mathrm{O} \mathrm{K}_{\mathrm{m}}$ se aproxima das demais preparações descritas na literatura, excetuando a do rim de camundongo $\left({ }^{16}\right)\left({ }^{17}\right)\left({ }^{18}\right)$.

\section{AGRADECIMENTOS}

Os autores desejam agradecer ao $\mathrm{CNPq}$ os auxílios recebidos durante a realização deste trabalho.

\section{SUMMARY}

Trebalose and Trebalase in Tenebrio molitor $L$.

Trehalose and trehalase were determined in the Tenebrio molitor L., using larva, pupa and imago.

A total number of 595 animals was analyzed. A growth curve up to the end of the larval stage was established (Fig. 1) and compared with the normal one obtained by Fraenkel. It was shown that trehalose and trehalase are more concentrated in the larva and imago presenting a curve with two arms as depicted in the Fig. 3 . Trehalase was expressed in $\mathrm{mg} / \mathrm{g}$ of Tenebrio and trehalase in $\mu \mathrm{g}$ of glucose /mg proteín.

\section{REFERÊNCIAS BIBLIOGRÁFICAS}

1 - COURTOIS. J. E. \& DEMELIER, J. F., 1966. Repartition de la Tréhalase chez l'homme et quelques mammifères - Bull. Soc. Chim. Biol. 48, 277.

2 - GILMOUR, D. 1961. Biochemistry of Insets. Academic Press. N. Y.

3 - DUTRIEN, J. \& ROLLAND, N. 1967. La Trehalase chez Tenebrio molitor. C. R. Soc. Biol. 161, 604.

4 - LEMONDE, A. \& VILLENEUVE, J. L. 1966. Les glucides de Tribolium confusum (Duval). Variations au cours de la metamorphose. Rev. Can. Biol. 25,11 .

5 - FRAENKEL, G., BLEWETT, M. \& COLES, M., 1950, The nutrition of the meal-worm Tenebrio molitor. Physiol. Zoo. 23, 92.

6 - LECLERECQ, J. 1948. Sur les besoins nutritifs de la larve de Tenebrio molitor L. Bioch. Bioph. Acta 2, 329.

7 - KALF, G. F. \& RIEDER. 1958. The purification and properties of Trehalase. J. Biol. Chem. 230, 691.
8 - SOMOGYI, M., 1930, A method for the preparation of blood filtrates. J. Biol. Chem. 86, 655.

9 - DUCHATEAU, Gh. \& FLORKIN, M. 1959. Sur la Trehalasémie des Insetes et sa signification. Arch. Int. Physiol. Bioch., 67, 306.

10 - ABREU, L. A., ABREU, R. A. \& VILLELA, G. G., 1956, Determination of Glycoproteins and glucose by the diphenilamine reaction. Rev. Bras. Biol. 16, 317.

11 - KINGSLEY, G. R. \& REINHOLD, J. G. 1949. The determination of true glucose in blood by reduction of ferricyanide. J. Lal, Clin. Med. 34, 713.

12 - LOWRY, O. H.. ROSEBOUGH, N. J., FARR, A. L. \& RANDALL, R. J. 1951. Protein Measurement with the Folin Phenol reagent. Jour. Biol. Chem. 193, 265. 
13 - PANEK, A., 1971, Mouse kidney trehalase. An. Acad. Bras. Cien, 43, 493.

14 - LECLERCQ, J. 1956. Elevage de deux race de Tenebrio molitor $L$. Bull. Soc. Roy. Sc. Liege, 6: 296.

15 - FRAENKEL, G. \& CHANG, P. L. 1954. Manifestations of a vitamin B- (carnitine) deficiency in the larvae of the meal worm Tenebrio molitor $L$. Physiol. Zood. 27, 40.
16 - GUILlOUX, E., COURTOIS, J. E. \& PERCHERON, F. 1968. Etude d' une Trehalase purifiée extrait de l'Hanneton. Bull. Soc, Chem. Biol. 50, 1915.

17 - HORIKOSHI, K. \& YKEDA, Y. 1966. Trehalase in conidia of Aspergilus oryzae. J. Bact. 2, 1883.

18 - LOPES, C. P. \& VILleLA, G. G. Trealase do Tenebrio molitor L. Ciência e Cultura 25(1). No prelo. 